\title{
Development of high heat resistant halogen-free cross-linked wire
}

\author{
Masaki NISHIGUCHI, Hitoshi YAMADA and Kiyoshi SAITO \\ The Furukawa Electric CO.,LTD. 6, Yawata Kaigandori, Ichihara, Chiba in Japan \\ TEL:+81-436-42-1717 FAX:+81-436-9359 e-mail:nishi@ch.furukawa.co.jp \\ (Received 27, September 2001 Accepted 7, December 2001)
}

\begin{abstract}
Halogen-free electric wires with superior heat resistance of $125^{\circ} \mathrm{C}$ and $150^{\circ} \mathrm{C}$ respectively have been developed, based on establishing proprietary technologies of flame retardance and an anti-aging agent system in addition to application of electron beam cross-linking. The halogen-free wires developed here proved to provide excellent mechanical properties and heat resistance, and were confirmed to meet the vertical flame retardance specifications of VW-1. The wires were subjected to chemical substance elution tests and combustion fumes analysis tests, and no toxic substances were detected with the wires.
\end{abstract}

Keywords: Halogen-free, Heat-resistance, Crosslink, Appliance wire

\section{INTRODUCTION}

In recent years, industrial wastes are causing serious social problems such that they might emit toxic heavy metals when disposed of in landfills and dioxins when combusted, thereby raising the environmental consciousness for waste reduction and product recyclability. Accordingly, electric wires for home appliances are increasingly required to be low in environmental impact and enhanced in recyclability.

Figure 1 compares the disposal systems of conventional wires and cables with that of environment-harmonized products. At present, while the conductor is recycled by $100 \%$, the covering material is mostly disposed of by landfills and incineration. Whereas lead compounds are often used as a stabilizer of polyvinyl chloride (PVC) --a general-purpose covering material for electric wires, these materials might elute when disposed of landfills contaminating the environment. For this, a countermeasure has recently been taken, in which lead is replaced by a new stabilizer so that lead-free materials are increasingly in use.

Furthermore, PVC is likely to emit toxic substances such as dioxins when combusted, since the polymer that constitutes PVC contains in itself chlorine --one of halogens. Although flame retardant materials based on polyethylene have been developed to replace PVC, the present situation is

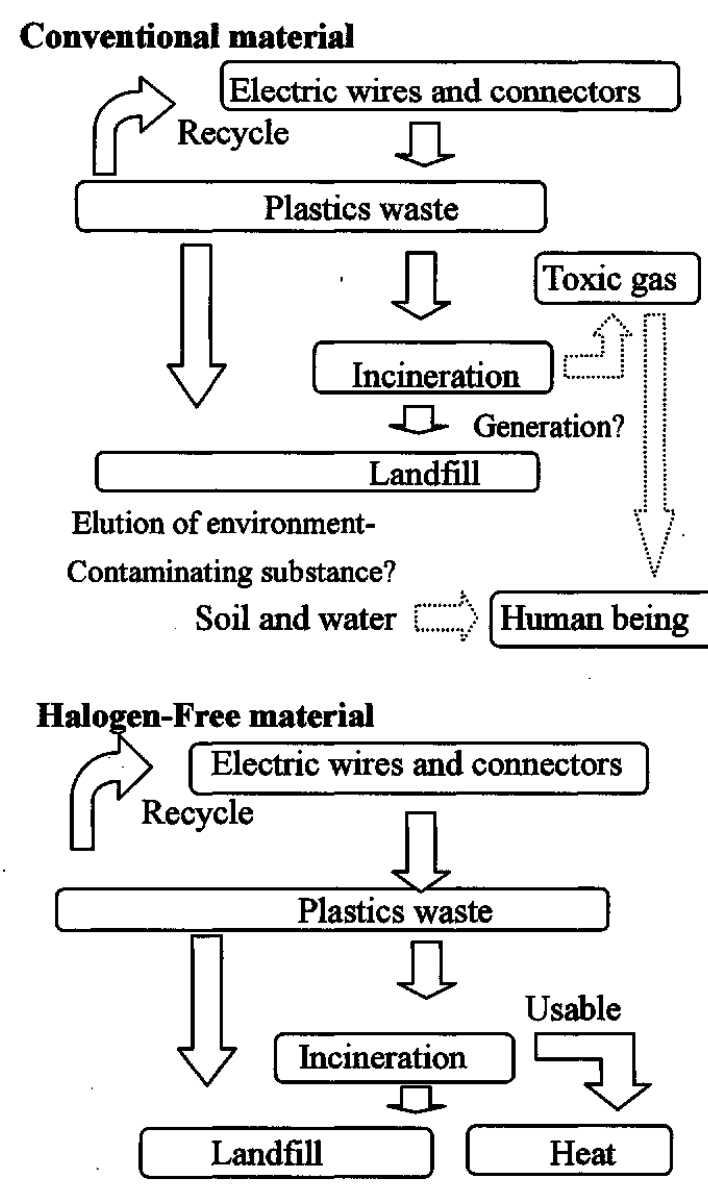

Fig. 1. Disposal systems for the conventional and environment-harmonized wires and cables. 
such that the materials uses halogen-based flame retardants to satisfy the required level of flame retardance.

To cope with such a situation, we have developed an environment-harmonized material together with electric wires using the material. While being provided with intrinsic properties equivalent to those of conventional materials, the new material contains neither halogens nor toxic heavy metals and thus imposes little impact on the environment.

As shown in Fig. 2, electric wires used for electric and electronic equipment are generally classified into those for inner wiring and those for power cords, and inner wiring wires are required to meet the stringent flame retardance regulation of vertical flame retardance (VW-1).

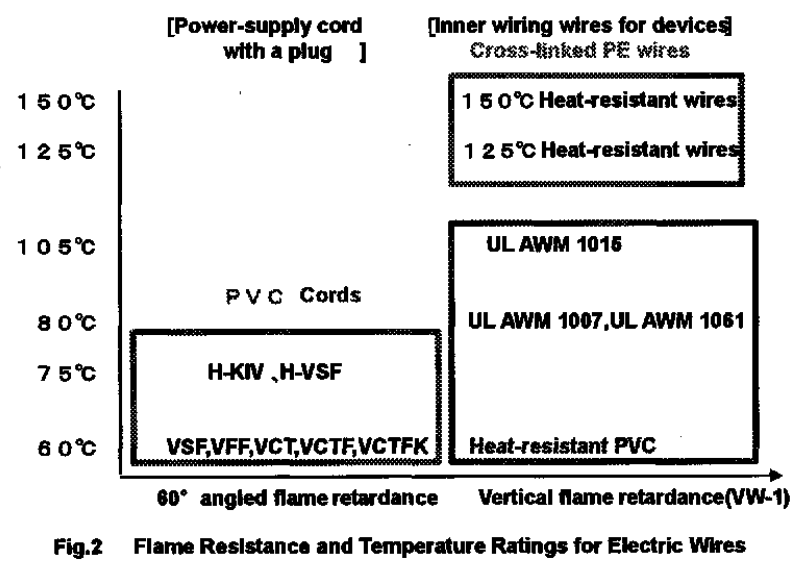

This paper reports on the development of halogen-free electric wires with superior heat resistance of $125^{\circ} \mathrm{C}$ and $150^{\circ} \mathrm{C}$, which can be used in home appliances such as air-conditioners. where conventionally heat-resistant cross-linked polyethylene wires were applied.

\section{PROBLEMS WITH FLAME- RETARDANT MATERIALS USED IN CONVENTIONAL WIRES}

Various developments of flame-retardant materials using no halogen compounds are known so far. However, since they are less effective in flame retardance than halogen-based materials, non-halogen flame-retardants have to be added in large quantities to ensure the desired level of flame retardance. This causes the following problems when compared with the conventional halogen flame retardants ${ }^{1}$ : ( Degradation in mechanical properties ${ }^{2}$
Degradation in formability, ${ }^{3}$ Degradation in termination workability; each of which will be discussed below.

\section{II-A. Degradation in Mechanical Properties}

Flame retardant dispersed in polymers degrades the mechanical properties of the material substantially, when the quantity added exceeds a certain level. Specifically, such properties as tensile strength, elongation, and abrasion resistance degrade in addition to flexibility.

\section{II-B. Degradation in Formability}

Inorganic flame retardants such as metal hydroxide reduce, when added to a large quantity, the fluidity of materials at the time of material melting, thus reducing the formability in extrusion or injection molding. The degradation in formability adversely affects the productivity and appearance of products. Especially in injection molding, it often results in poor molding.

\section{II-C. Degradation in Termination Workability}

Electric wires are usually removed of their covering on their ends and terminated with connectors. Insufficient termination workability leads to covering residuals formation on the exposed conductors due to unsuccessful cutting, thus causing poor electrical contacts.

\section{DEVELOPMENT AND EVALUATION OF PRODUCTS}

Two types of halogen-free compound for electronic wires to be cross-linked have been developed, based not only on a proprietary technology of flame retardance that uses metal hydroxides eliminating phosphorous compounds and toxic metals, but also on the establishment of an anti-aging agent system. Furthermore, halogen-free electric wires with heat resistance of $125^{\circ} \mathrm{C}$ and $150{ }^{\circ} \mathrm{C}$ have been developed, in which these compounds are applied on the conductor followed by electron beam cross-linking.

The developed compounds were evaluated for mechanical strength, flexibility, and flame retardance.

Moreover, the developed electric wires were subjected to evaluation tests for UL code characteristics(show table2), stripping workability, and abrasion resistance.

In addition, the wires underwent environmental 
impact evaluation tests assuming incineration and landfills. Burning test was carried out in compliance with JS K 7217, in which a sample was burnt at $750^{\circ} \mathrm{C}$ for $30 \mathrm{~min}$, and the emitted gas was absorbed for quantitative analysis of chlorine and bromine by ion chromatography. Elution test of toxic substances was carried out based on the Notice No. 13 of the Ministry of the Environment, in which chemical substances were elution tested.

\section{DISCUSSIONS}

\section{IV-A. Characteristics of the Developed Halogen-Free Material}

Table 1 shows the characteristics of the halogen-free compound developed at this time.

As can be seen, the flame retardance is excellent with an oxygen index of 49 . In terms of

Table 1. Characteristics of halogen-free compounds.

\begin{tabular}{|c|c|c|}
\hline & $\begin{array}{c}125^{\circ} \text { Ctype } \\
\text { compound }\end{array}$ & $\begin{array}{c}150^{\circ} \text { Ctype } \\
\text { compound }\end{array}$ \\
\hline $\begin{array}{c}\text { Tensile strength } \\
\text { (MPa) }\end{array}$ & 11.2 & 10.5 \\
\hline Elongation (\%) & 120 & 120 \\
\hline Hardness A & 94 & 93 \\
\hline Oxygen index & 49 & 49 \\
\hline UL94 V-0 (1.6mm) & Passed & Passed \\
\hline UL94 V-0 (0..5mm) & Passed & Passed \\
\hline
\end{tabular}

UL94 burning tests also, the material was confirmed to be in compliance with the V-0 level with small sheet thicknesses of $0.5 \mathrm{~mm}$ as well as of $1.6 \mathrm{~mm}$. Thus, the excellent flame retardance of the developed halogen-free material has been demonstrated. The hardness was indicated as $94 \mathrm{~A}$, equivalent to that of the conventional material for cross-linked polyethylene wires.

\section{IV-B. Characteristics of Developed Halogen-Free Wire}

Figure 3 shows the appearance of the developed halogen-free wire. It permits arbitrary coloring, and shows excellent performance in terms of abrasion resistance

that is often a disadvantage of halogen-free electric wires.

Table 2 shows the characteristics of the halogen-free wire. It has been confirmed that the developed wires are provided with excellent mechanical characteristics, deformation property,

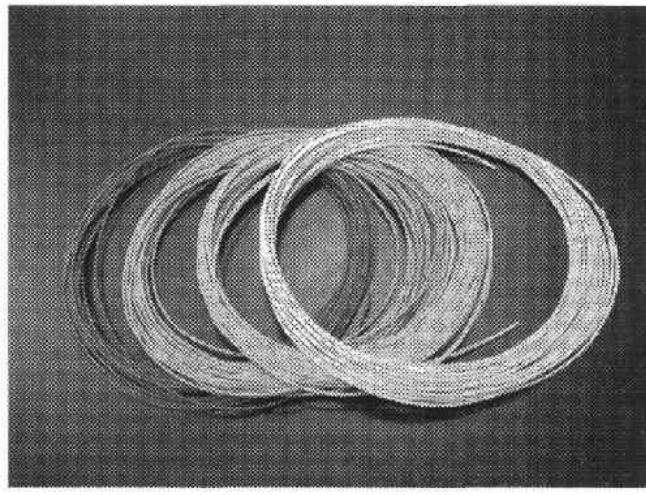

Fig.3 Appearance of developed halogen-free wire

Table 2. Characteristics of halogen-free electric wires.

\begin{tabular}{|c|c|c|c|}
\hline & $\begin{array}{c}125^{\circ} \mathrm{C} \\
\text { heat-resi } \\
\text { stant } \\
\text { wire }\end{array}$ & $\begin{array}{c}150^{\circ} \mathrm{C} \\
\text { heat-resi } \\
\text { stant } \\
\text { wire }\end{array}$ & $\begin{array}{l}\text { UL } \\
\text { code }\end{array}$ \\
\hline Elongation (\%) & 160 & 160 & $100<$ \\
\hline $\begin{array}{c}\text { Tensile } \\
\text { strength }(\mathrm{MPa})\end{array}$ & 12 & 12 & $10.3<$ \\
\hline $\begin{array}{c}\text { Deformation } \\
(\%)\end{array}$ & 29 & 33 & $50>$ \\
\hline $\begin{array}{c}\text { Low-temp. test } \\
\text { At }-10^{\circ} \mathrm{C}\end{array}$ & Passed & Passed & Passed \\
\hline VW-1 & Passed & Passed & Passed \\
\hline Aging test & $\begin{array}{l}158^{\circ} \mathrm{C} \\
168 \mathrm{Hr}\end{array}$ & $\begin{array}{l}180^{\circ} \mathrm{C} \\
168 \mathrm{Hr}\end{array}$ & \\
\hline Red. El (\%) & 82 & 75 & $65<$ \\
\hline Red. T.S.(\%) & 118 & 117 & $70<$ \\
\hline
\end{tabular}

and heat resistance, and their flame-retardance is in compliance with the vertical flame-retardance specifications (VW-1).

The developed wires were tested to evaluate their termination workability (stripping property) using an automatic termination machine equipped with a flat service knife and the results are shown in Fig. 4. Notwithstanding the fact that a wire covering material that uses polyolefin as base material shows poor stripping property, the developed wires proved to have a cutting property almost equivalent to that of conventional cross-linked heat-resistant wires. 

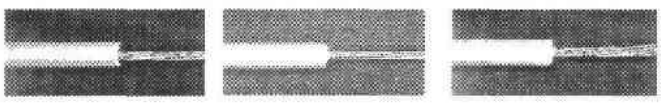

Fig.4. Workability of developed halogen-free wires.

\section{IV-C. Evaluation of Environmental Impact}

The developed wires were also subjected to chemical substance elution tests and combustion fumes analysis tests. The results are shown in Table 3 and 4 .

As the result, no chlorine, bromine, nor cyanic gases were detected.

At the chemical substance elution tests, toxic heavy metals, cyanogen, antimony and the like were not detected, nor halogenides and cyanides in the combustion tests. It was thus confirmed that the halogen-free electric wires developed at this time do not emit substances that may adversely influence the environment when they are eventually disposed of by incineration and landfills.

Table 3. Gaseous contaminants detected.

\begin{tabular}{|l|l|l|}
\hline & Result & Ceiling \\
\hline Cl Compound & None & $0.3 \mathrm{mg} / \mathrm{g}$ \\
\hline Br Compound & None & $0.3 \mathrm{mg} / \mathrm{g}$ \\
\hline Cyan Compound & None & $0.1 \mathrm{mg} / \mathrm{g}$ \\
\hline
\end{tabular}

\section{SUMMARY}

Halogen-free electric wires containing no toxic heavy metals and phosphoric compounds provided with superior heat resistance of $125^{\circ} \mathrm{C}$ and $150^{\circ} \mathrm{C}$ have been developed as a substitute for flame retardant, heat-resistant, cross-linked polyethylene insulated wires. The wires have already acquired certification of the Electrical Appliance and Material Control Law and the UL code.
Table 4. Chemical contaminants detected.

\begin{tabular}{|l|l|l|}
\hline & Result & Celling \\
\hline $\mathrm{CN}$ & None & $0.1 \mathrm{mg} / \mathrm{L}$ \\
\hline $\mathrm{Cr}$ & None & $0.02 \mathrm{mg} / \mathrm{L}$ \\
\hline $\mathrm{Hg}$ & None & $0.0005 \mathrm{mg} / \mathrm{L}$ \\
\hline $\mathrm{Pb}$ & None & $0.01 \mathrm{mg} / \mathrm{L}$ \\
\hline $\mathrm{Cd}$ & None & $0.002 \mathrm{mg} / \mathrm{L}$ \\
\hline $\mathrm{As}$ & None & $0.01 \mathrm{mg} / \mathrm{L}$ \\
\hline $\mathrm{Se}$ & None & $0.03 \mathrm{mg} / \mathrm{L}$ \\
\hline $\mathrm{Sb}$ & None & $0.004 \mathrm{mg} / \mathrm{L}$ \\
\hline
\end{tabular}

\section{Notice NO.13 by Environmental Agency Detection method for metals and other substances involved in industrial wastes}

The halogen-free wires have been confirmed to emit no chloric gases, bromic gases, and cyanic gas when combusted, nor emit toxic heavy metals and toxic chemical substances at elution tests. Thus, the developed wires are environment-harmonized electric wires indeed with very low environmental impact.

These wires are expected to find a large market as a heat-resistant electric wire for home appliances as well as recyclable products in general.

\section{REFERENCES}

${ }^{1}$ Sakamoto, K.Macknight, W.J. :J. Polym. Sci.,26, 449(1981)

2 Earnest, t.r.,Jr. Macknight W. J. .J. Polym. Phys. Ed.,16, 143 (1978)

${ }^{3}$ Cox. W. P. and Merz, E. H. :J. Polym. Sci.,27, 2189(1989)

Presented at the $5^{\text {th }}$ International Conference on ECOMATERIALS Oct. 2-4, 2001,Honolulu, Hawaii 